This manuscript has been accepted by IEEE for publication (C) 2007 IEEE. Personal use of this material is permitted. Permission from IEEE must be obtained for all other uses, in any current or future media, including reprinting/republishing this material for advertising or promotional purposes, creating new collective works, for resale or redistribution to servers or lists, or reuse of any copyrighted component of this work in other works. The full reference is:

\title{
Modelling of currents on Long Span, Dielectric Cables on HV Overhead Lines
}

IEEE Trans PDel 22 Issue 2, (2007) 1138-1144

S M Rowland, K Kopsidas, I Cotton

DOI: $10.1109 /$ TPWRD.2007.893434 


\title{
MODELING OF CURRENTS ON LONG SPAN, DIELECTRIC CABLES ON HV OVERHEAD LINES
}

\author{
Simon M. Rowland, Konstantinos Kopsidas, Ian Cotton
}

\begin{abstract}
It is well established that all-dielectric, selfsupporting cables on high voltage overhead power lines can suffer from damage through the mechanism of dry-band arcing. A number of heuristics have evolved over the past 20 years and these are used to determine whether such cables are capable of reliable performance. A key element to planning is modeling the installation conditions. In addition to the geometry of the high voltage line, such a model needs to consider the climatic environment and potential pollutants on the cable. In this paper a model is built based on the commercial software CDEGS (Current Distribution, Electromagnetic Fields, Grounding and Soil Structure Analysis) which is widely used in the power industry. The model developed is shown to be consistent with a number of previously published models. It is demonstrated that the relative sags of all-dielectric self-supporting cable and conductors is key to the severity of the installed situation. It is also shown that the towers do not need to be modeled for the most severe cases of high pollution, but are required for accuracy in medium and low pollution cases.
\end{abstract}

Index Terms - ADSS cable, dry-band arcing, modeling, CDEGS, transmission lines, high voltage, currents.

\section{INTRODUCTION}

The growth of the internet and telecommunications has increased the demand for communication paths able to transfer large amounts of data. Deploying optical fiber cables on existing overhead power lines often provides a fast and low-cost route to achieving this objective. A variety of cable types can be used to this end [1]. The most widely used have been the optical ground wire (OPGW) and the all-dielectric self supporting (ADSS) cable. Correctly designed cables ensure that optical transmission is virtually free of interference from electrical and other environmental factors. However, the ADSS cable suffers from a form of surface degradation known as dry-band arcing, which can lead to complete mechanical and thus optical failure of the cable.

Dry-band arcing on optical cables has been studied over the past 20 years. As a result cable design has been improved,

Manuscript received September 9, 2005.

The authors are with The School of Electrical and Electronic Engineering, The University of Manchester, PO Box 88, Manchester, M60 1QD, UK: phone: +44 161306 4720; (e-mail: s.rowland@manchester.ac.uk). mainly through the development and use of better sheathing materials. Other solutions have been proposed and tested to various extents, and normally involve the introduction of a limited degree of conductivity into the cable $[2,3,4]$. One feature of this dry-band arc phenomenon is that it only occurs because of the large scale of the overhead lines and the resulting capacitive coupling between optical cable, conductors and ground. Thus, modeling the ageing processes in the laboratory is not straightforward and activity continues to develop suitable tests and verify their validity [5].

This paper is concerned with theoretical modeling of potential installations so that the severity of any particular route can be predicted. The work utilizes a commercial software package and extensively refers to other researchers' activities for comparison and verification. The issues of modeling service conditions are addressed, so that the electrical environment of an ADSS cable can be better understood. One of the key parameters of such a model is the conductivity per unit length of the cable. This conductivity varies in time, by weather and pollution changes, and identifying its value is itself a challenging issue [6]. This is particularly important if the model of dry-band arc compression as a failure mechanism $[7,8]$ is to be considered, since in that case very infrequent weather conditions may control the cable's life expectancy rather than typical or average conditions.

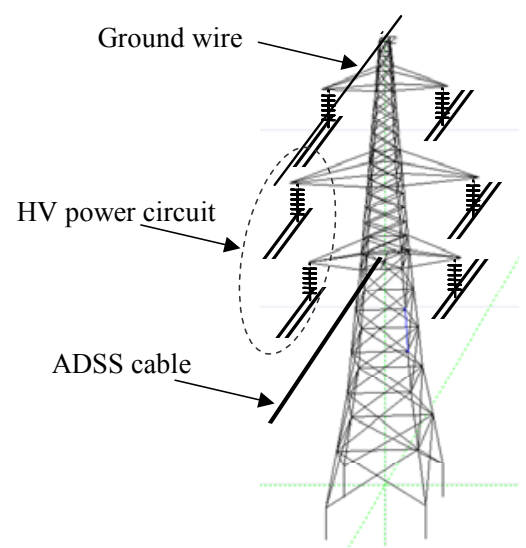

Fig. 1. Typical location of an ADSS cable on a twin circuit tower. 


\section{THE ORIGIN OF CURRENTS ON ADSS CABLES}

Typically, an ADSS cable is suspended on a lattice tower between the phase conductors at the height of the lower crossarm as shown in Fig. 1. The choice of location of the ADSS cable on the tower is normally driven by mechanical considerations such as existing fixing locations on the tower, ground clearance and clearance from conductors.

The ADSS cable houses optical fibers for telecommunications [1]. The construction of the optical cable is not of importance to this analysis. Essentially it is modeled as an insulating rod. A resistance per unit length is ascribed to a thin layer of pollution on its surface, and is represented schematically in Fig. 2 as a linear resistance $R$, while $C_{1}$ and $C_{2}$ are distributed capacitances to a phase conductor and ground respectively. $\mathrm{R}$ depends upon the moisture and amount of pollution on the sheath surface. The cable diameter is typically designed to be between 14 and $16 \mathrm{~mm}$.

The cable is fixed to the tower by metallic clamps. These also provide low resistance paths to ground, and are assumed here to be of negligible resistance. The clamps are fixed over metallic armor rods which are designed to spread the mechanical clamping load on the cable. These are of the order of $2 \mathrm{~m}$ long and totally enclose the cable in the region of the clamp. It is through these metallic armor rods that current flows to ground from the ADSS cable.

Fig. 2 shows a schematic of the electrical situation for the ADSS cable. Essentially this is a simplified transmission line model. The resistor represents the ADSS cable sheath resistance and the capacitor $\mathrm{C}_{1}$ represents the coupling capacitance between the ADSS cable and one of the phase conductors. The capacitance between the tower and the ADSS cable has been ignored in this schematic. This approach has been widely used for calculating the coupling capacitance between the many conductors and the ADSS optical cable as described in the following section.

\section{DRY-BAND ARCING}

Dry-band arcing arises on an ADSS cable as a result of currents on its surface. The currents can have values of up to $10 \mathrm{~mA}$ when the cable is wet and heavily polluted, although values of $0.1 \mathrm{~mA}$ are more typical. These currents produce Joule heating in the moisture on the cable surface, for example pollution on a cable gives a resistance per unit length of 1 $\mathrm{M} \Omega / \mathrm{m}$, and $5 \mathrm{~mA}$ results on the cable close to the tower, 25 $\mathrm{W} / \mathrm{m}$ will be generated. Any local region that adventitiously has a higher resistance will experience higher heat output and thus dry faster. This positive feedback process results in classical dry-band arc formation. As shown below, the current is controlled by the cable's distributed resistance, and a small high resistance region does not significantly influence the current flowing. Once this dry-band is established, and if sufficient voltage and current are available, a stable dry-band arc can be formed. It is found that once an arc is established the dry-band length is similar to the diameter of the cable $(\sim 14$ $\mathrm{mm})$. The arc will normally be extinguished by additional precipitation reducing the resistance of the dry-band, or by the dry-band extending in length due to continued Joule heating so that insufficient voltage is available to strike an arc. Dryband arcs lead to localized heating of the cable sheath and can lead to tracking, melting or erosion depending upon the sheath material and the nature of the arc (principally controlled by its current).

Determining the likely voltage and current available to an arc is thus critical in determining which sheath is suitable for any application. If insufficient voltage or current is available then stable arcing is not possible and the situation is benign.

There is no consensus on the conditions required to age or damage a cable. A heuristic frequently used is that a 'standard' (by which is meant medium density polyethylene) sheath is satisfactory for cables which are deployed in space potentials up to $12 \mathrm{kV}$. Above this voltage 'track-resistant' sheaths should be used. Such sheaths are typically aluminium trihydrate filled EVA blends [9,10]. Rowland and Nichols have previously argued that current should be the key parameter for application engineering [8]. More recently Tuominen and Olsen [11] suggest $1.5 \mathrm{~mA}$ and $26 \mathrm{kV}$ are the limits for standard sheaths and $5 \mathrm{~mA}$ is a limit for 'track resistant' sheaths.

All models of degradation consider a continuous gradual ageing in two phases. Firstly, a hydrophobic sheath gradually becomes hydrophilic over several years of low current surface discharges and natural UV radiation. Secondly, once the sheath is hydrophilic, dry-band arcing occurs occasionally throughout the cable's remaining life, gradually degrading its surface through tracking or erosion. Rowland and Easthope [7] offer an additional third step in which it is possible for a rare condition to arise in which a dry-band is dynamically shortened in length creating very severe damage in just a few seconds of aggressive activity.

Much work needs to be carried out before the mechanisms of ageing are clarified and the uncertainties of life prediction are reduced.

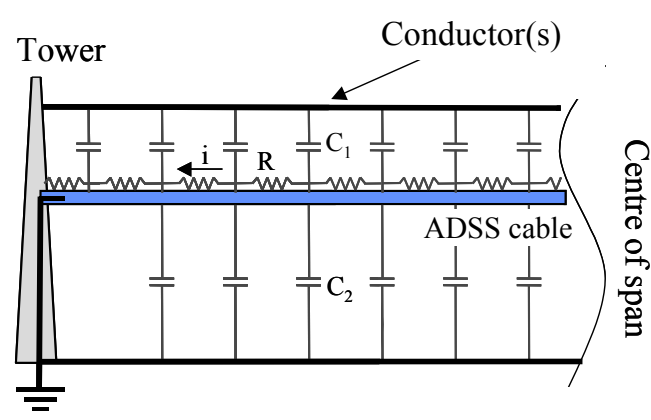

Fig. 2. Schematic of the electrical environment of the ADSS cable. Only one conductor is shown for clarity. 


\section{PREVIOUS MODELING WORK}

The typical voltage profile along a uniformly polluted ADSS cable is shown to display a single peak at the span centre. Associated with this curve the current on the ADSS cable is seen to peak at the towers and be zero at mid-span, Fig. 3. The magnitude of the current and voltage is dependent upon the line geometry and the resistance of the cable [12].

Under certain conditions, such as when the ADSS cable has a high resistance, it has been shown that voltage can peak at two positions within the span $[8,13]$, and that the associated current still has a continuously increasing value from midspan to the tower. The reason that at the location of a voltage peak (i.e. zero voltage gradient) we can still see a current is not immediately obvious. However, if the source of the current to the cable is considered it is explicable. Not only does the voltage gradient on the cable drive the current on the cable, but we must consider the current driven through the capacitances between the cable and the phase conductors and earth plane, $\mathrm{C}_{1}$ and $\mathrm{C}_{2}$ of Fig. 2, and the resulting phase shift with the additional current. The dip in magnitude of the space potential is associated with a change in current direction which cannot be identified from the current magnitude plots typically published. Thus, to get a complete picture of the voltage and current profile we need information on the phase of the voltage and current along the cable length.

Carter and Waldren [12] developed an analytical approach to the problem enabling an understanding of the process [14]. Peacock and Wheeler [15] utilized FEA to develop a profile of space potential magnitude at mid-span. Berkers and Wetzer [16] developed similar results from a transmission line model. Smith produced a more sophisticated analytical model for Corning Cables that allowed for differential sag between the ADSS cable and the conductors, and blow-out of the cable (lateral movement of the cable caused by wind), but this was not published. Smith's work also facilitated modeling of a novel solution to the problem [14,17]. More recently Tuominen et al $[11,13]$ have published a model based on the commercial package PSPICE using lumped components and produced a model capable of considering differential sag and the effect of the presence of the towers for a single circuit, three phase system. These models are referred to in section VI for comparison with this work.

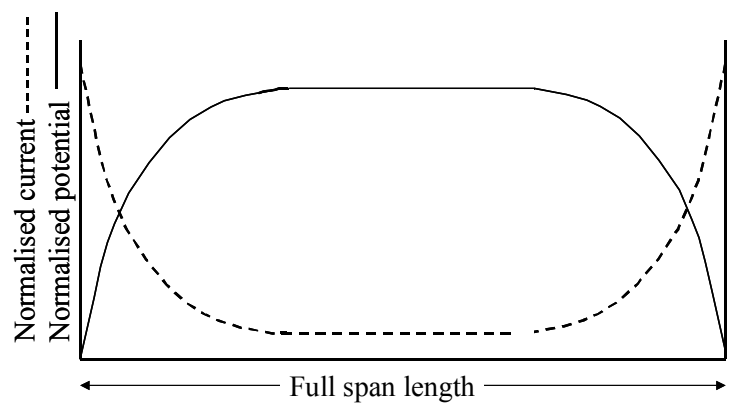

Fig. 3. Typical plots of current and voltage along an ADSS cable length in which a tower is located each end of $\mathrm{x}$-axis $300 \mathrm{~m}$ apart.

\section{THE MODEL}

The work reported here utilises the commercial package CDEGS and in particular the sub package HIFREQ. The CDEGS package is based on a series of mathematical equations referred to both field theory and circuit analysis. As a result, CDEGS is a suitable tool for this application.

The HIFREQ package can calculate current distributions for networks of overhead conductors and metallic grids. From the current distributions, HIFREQ calculates electric fields and scalar potentials at in-air and in-soil field observation points [18].

The modeling construction is confined to building blocks of straight conductors (i.e. cylindrical physical shapes with a minimum length equivalent to their diameter). The resulting simulation procedure is time-consuming and therefore some simplifications of the ADSS cable system have been made. Firstly, the conductive pollution layer on the cable was modeled by altering the resistivity of the whole cable, which was assumed to be homogeneous through its cross-section. Thus, a change in pollution level was modeled by an equivalent alteration in uniform cable resistivity. Another simplified structural detail was the suspension assembly (i.e. the clamp at each tower). Its electrical structure is effectively a hollow conductor through which the ADSS cable passes. This was represented as a solid metallic section of the cable with electrical characteristics identical to the tower structure. Where there was no tower in the simulation model each suspension assembly was fixed to ground potential. The insulators between the conductors and the towers were modeled as air gaps. Finally, the structure of the suspension towers is composed of bolted metal bars with different crosssections and sizes. Within CDEGS, the towers are given the same frame dimensions but each metal bar is represented by a cylindrical conductor with the same diameter and resistivity. The resistive path of the current through the tower or the earth clamps will not be significant in determining the voltages and currents on the ADSS cable so these simplifications can be made without penalty. Cables and conductors with sags were built in the model by approximating each geometry to a series of straight conductors $1 \mathrm{~m}$ in length.

\section{COMPARISON WITH PREVIOUS MODELS}

The case of twin three-phase circuits was considered to verify the model against the work of Carter and Waldron [12] and Smith [14]. These two models use different techniques, and have previously been shown to be in close agreement with each other. The Smith model has also been verified against full-scale field measurements [4]. The results against which this model was verified did not allow for conductor or cable sag, nor were towers modeled. The system voltage was 400 $\mathrm{kV}$.

Fig. 4 shows the contours of mid-span space potential perpendicular to the conductors calculated using CDEGS. Two phase arrangements have been considered while 
conductors sag and towers were neglected. Fig. 5 shows the equivalent results taken from [14]. It can be seen that the results are in good agreement. Small discrepancies are probably caused by differences in assigned values of sizes of the towers and from differences in conductor resistivities.

Tuominen and Olsen [11] produced a model for a single circuit tower. Two of their results are illustrated in the two graphs on the right hand side of Fig. 6. This shows, for one half of a $300 \mathrm{~m}$ span, the magnitude of the current developed on the ADSS cable with $100 \mathrm{k} \Omega / \mathrm{m}$ resistance. Calculations for three different values of differential sag are provided (the differential sag is the difference between the sag of the conductor and the ADSS cables when expressed as a percentage of the span length). The upper and lower graphs in Fig. 6 shows a significant impact when the phasing of the conductors is changed. The graphs on the left hand side show the equivalent calculations from the CDEGS model. Once again the predictions are identical.
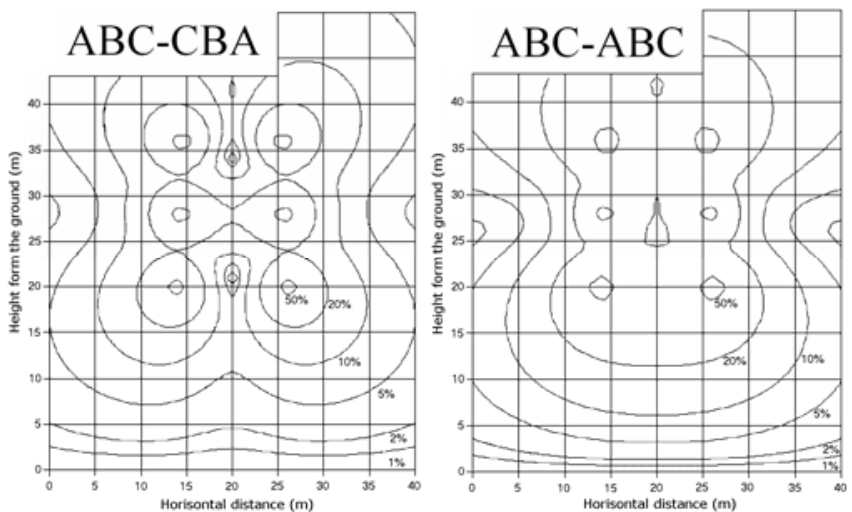

Fig. 4. Space voltage potential contours perpendicular to a double $400 \mathrm{kV}$ transmission line for different phasing patterns as produced by CDEGS.
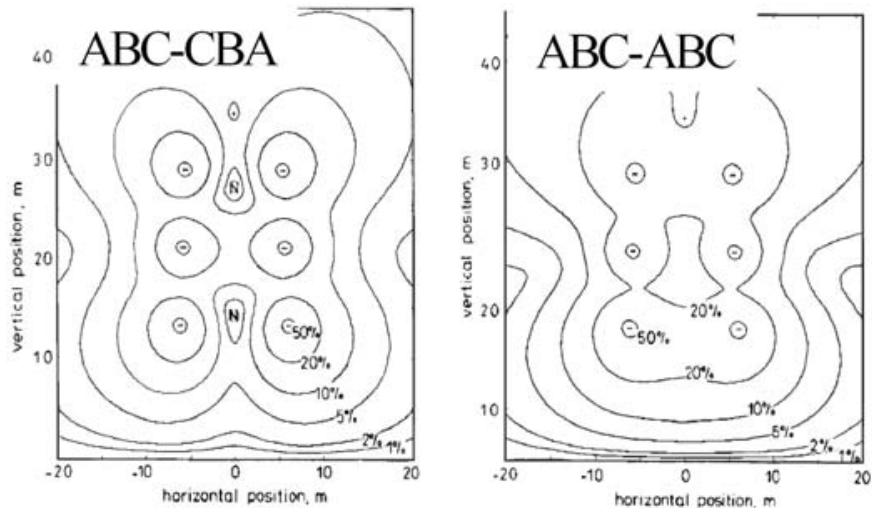

Fig. 5. Two data sets equivalent to Fig.4 from [14].
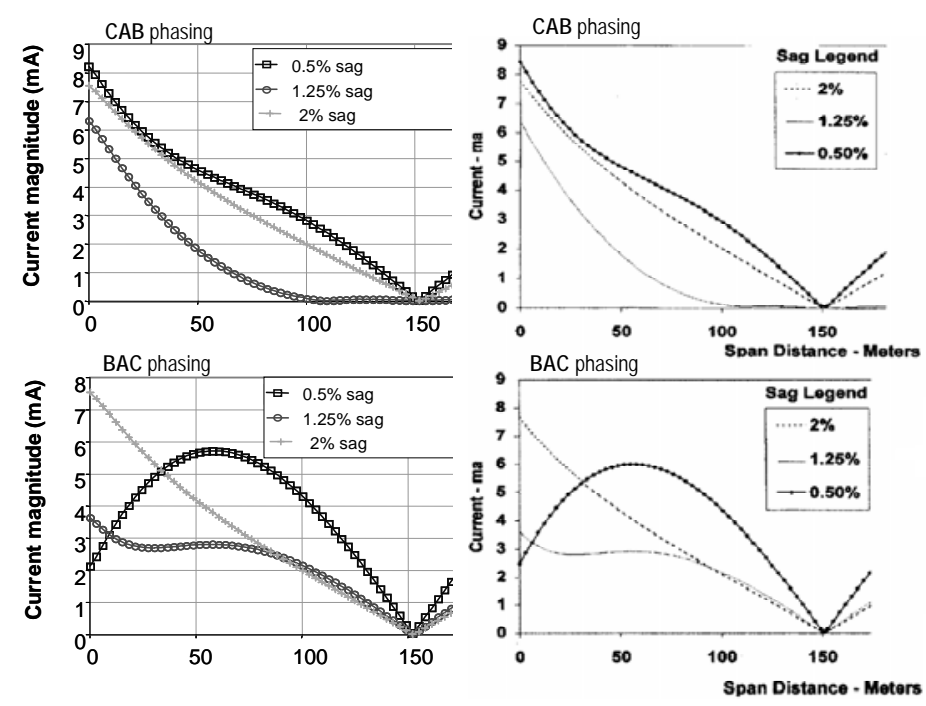

Fig. 6. Magnitude of current on the ADSS cable of $100 \mathrm{k} \Omega / \mathrm{m}$ erected on single circuit lattice towers. The power circuit phasing is different for the upper and lower graphs.

\section{THE IMPACT OF THE TOWER}

In the previous section it was shown that the model constructed is consistent with previously published work. The model complexity is now increased to identify the impact of the tower structure.

Karady et al [13] previously showed, using a lumped circuit approach, that the presence of a tower had little effect on their calculated currents and fields. Using the CDEGS platform a physical model of a tower can also be built and put into the model. A transmission suspension lattice tower (D STD) was chosen according to UK standards for a $400 \mathrm{kV}$ double circuit with a span length of $360 \mathrm{~m}$. Each phase conductor in the model has a radius that represents a twin conductor system [18]. The model configuration can be seen in Fig. 7.

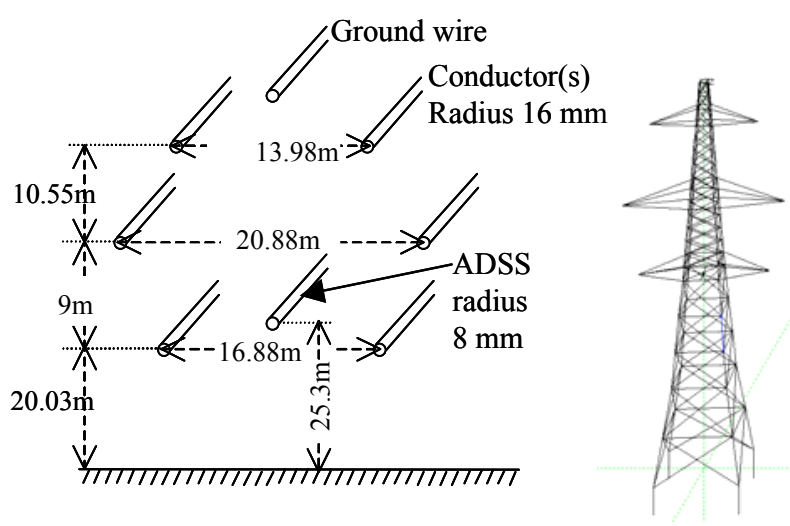

Fig.7. Basic structure dimensions of twin circuit tower extensively used in this work. 
Fig. 8a shows the current and voltage magnitude developed on the $50 \mathrm{~m}$ adjacent to the tower of a $300 \mathrm{~m}$ span for ABC-ABC phasing pattern with and without towers in the model. It can be seen that the presence of a tower only affects the current at a distance up to 5 to $6 \mathrm{~m}$ from the tower. It can also be seen that the current magnitude in the last $2 \mathrm{~m}$, where the cable is inside the tower body, remains relatively constant. This is because the tower shields the ADSS cable from the conductors, preventing additional current in this region, and maybe even draws some current to ground capacitively. The choice of cable resistance for this model was $100 \mathrm{k} \Omega / \mathrm{m}$ in line with that chosen by Karady et al [13]. This result is very similar to Karady's. What Karady did not show however is that the relative impact of the tower increases with ADSS cable resistance, although all the current magnitudes decrease. Fig. 8 b shows the impact on the same geometry for a $3 \mathrm{M} \Omega / \mathrm{m}$ cable. The effect is significantly more pronounced with a reduction in peak current at the towers of approximately $30 \%$. Voltage gradients are not affected by the tower in either case. The voltage gradient is considerably reduced for the more conductive cable compared to the very resistive case.

\section{VIII.THE IMPACT OF DIFFERENTIAL SAG}

The tensile modulus of the conductors and the ADSS cables are very different and as a result they are normally strung with different tensions and sags. Typical values for a conductor are $3 \%$ and for an ADSS cable $1.5 \%$. These values change with conductor temperature and local practice. This means that the relative position of the conductors and ADSS cable change considerably across a span. Small variations in sag percentage can give rise to large movements of the ADSS cable relative to the positions of the conductors. It may well be that the designed sag difference means that the ADSS cable is fixed to the tower mid-way between the bottom four phase conductors, but at mid-span is mid equidistant from the top four. Data presented here consider the impact of such sag differentials. Towers are not modeled in the results presented in this analysis.

To demonstrate how the current and voltage distributions depend on the phasing pattern, models with and without sag are shown for an $\mathrm{ABC}-\mathrm{ABC}$ arrangement in Fig. 9, and $\mathrm{ABC}-$ CBA in Fig. 10. A $360 \mathrm{~m}$ span distance was chosen and three different resistivities were modeled for the ADSS cable.

\section{DISCUSSION}

The optical cable is usually positioned at the middle of the lowest cross-arm of the tower because of the mechanical convenience of this point (Fig. 1). As can be seen in Figs. 4 and 5, this is close to the null point, which is formed when the phasing pattern is ABC-CBA. However, when the symmetrical configuration $\mathrm{ABC}-\mathrm{ABC}$ is considered the space potentials in this region are more severe. Hence this pattern is also shown. Consequently, the phasing combination changes the voltage potential on the optical cable surface from less than $10 \%$ to something above $20 \%$. It should also be noted that often the worst case seen is when one of the circuits is switched out $[1,14]$. The issue here then is that it is clearly necessary to consider all the possible phase arrangements in the cable's life including phase outages.
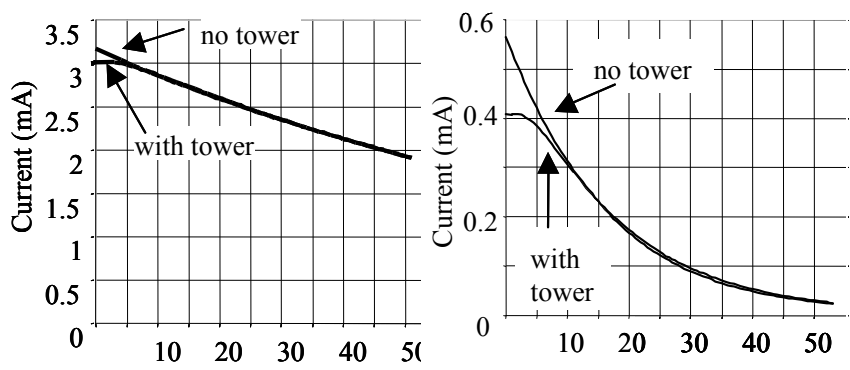

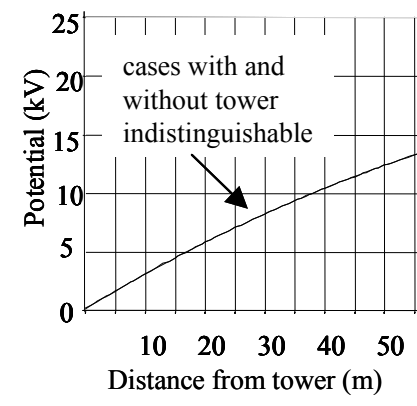

(a)

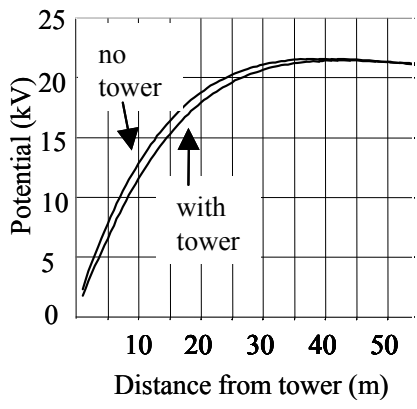

(b)
Fig.8. The effect of including towers on the model on current magnitude and on potential along the cable length for a) $0.1 \mathrm{M} \Omega / \mathrm{m}$ cable, b) a $3 \mathrm{M} \Omega / \mathrm{m}$ cable. Note the current scale is different in each case. (a)
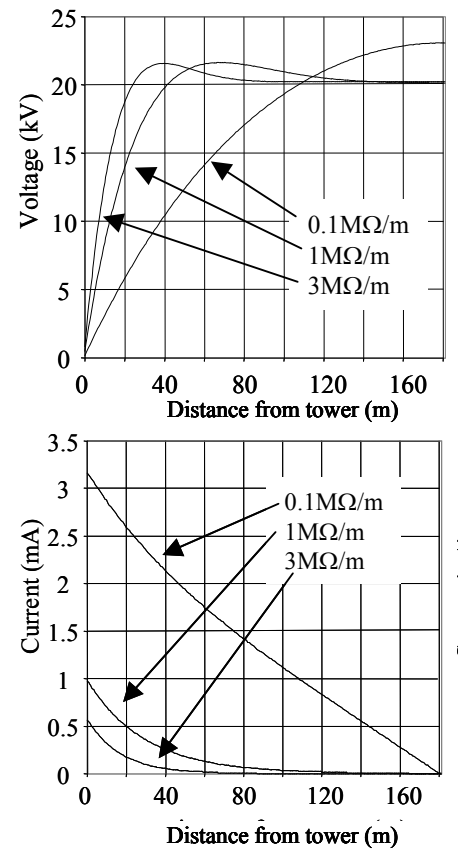

(b)
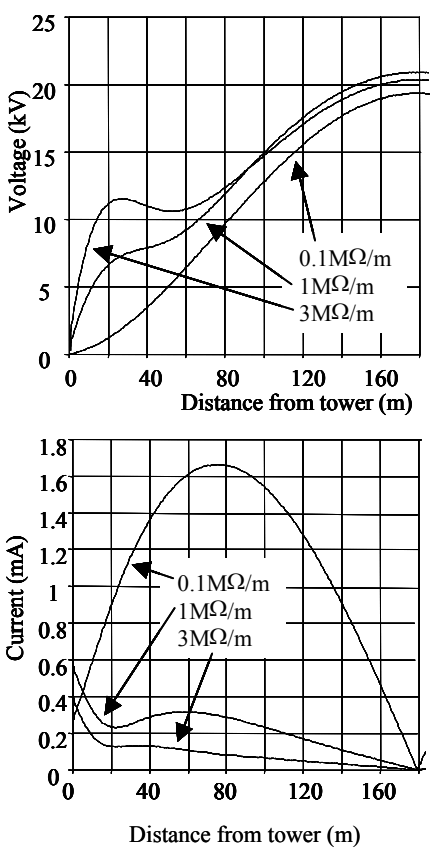

Fig. 9. Results for ABC-ABC phase arrangement with (a) no difference in sag and (b) a $1.5 \%$ difference in sag for different pollution levels. 

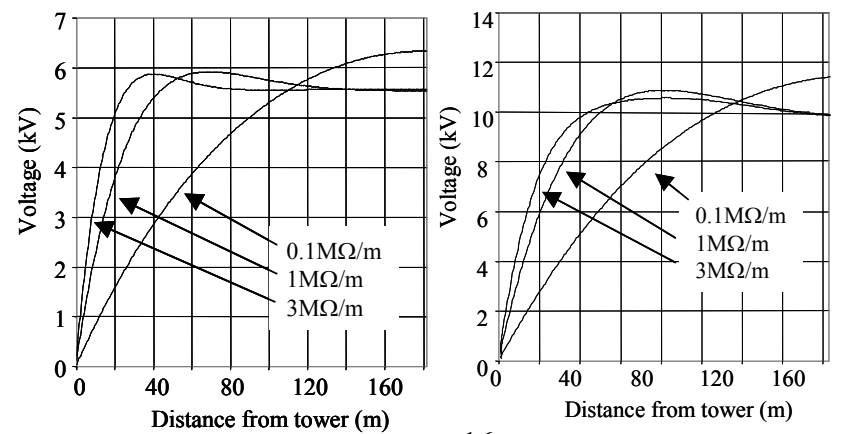

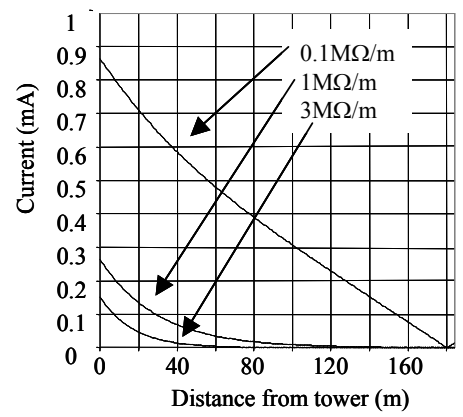

(a)

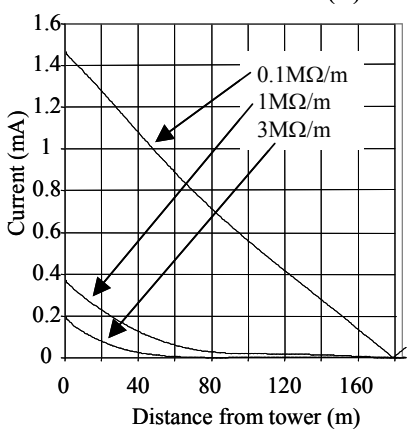

(b)
Fig. 10. Results for ABC-CBA phase arrangement with: (a) no difference in sag, (b) $1.5 \%$ difference in sag.

The most aggressive conditions for the cable are to be found when the conductivity of the pollutant on the cable is high. The effect of the tower on the calculation is negligible at very high conductivities $(100 \mathrm{k} \Omega / \mathrm{m})$, as observed by Karady et al [13]. However it has been shown that at higher, more realistic cable resistivities the tower can make a significant difference to the current to ground. This is primarily because the distance over which current is gathered is smaller in the high resistance case and so the length affected by the tower capacitance is of more importance. The tower does not significantly alter the voltage profile experienced by the cable or the voltage available to drive an arc. The presence of the tower must always reduce the current to ground and so when calculating the situation of any installation, ignoring the tower will always give a worst case analysis, and can be justified on that basis. The cases examined here suggest that in the more onerous situation of high pollution this approximation is a good one. This certainly helps application engineers use lumped circuit models, and speeds up processing within CDEGS.

It is immediately clear by comparing the magnitude of the currents in Figs. 9 and 10 that introducing sag can radically alter the voltage profile and the resultant currents. Also the current no longer necessarily peaks at the tower if differential sag is considered. This is in agreement with previous findings [11].

By studying the graphs for the $\mathrm{ABC}-\mathrm{ABC}$ arrangement in Fig. 9 , it is observed that differential sag reduces the values of the maximum current and also changes the position where these values are developed on the dielectric cable when its resistance is $0.1 \mathrm{M} \Omega / \mathrm{m}$. Specifically for this situation, the current is maximum at that distance from the tower where the ADSS cable has the same height as the conductors with the middle phase.

In the cases of cables with larger resistances, which are more representative of a working situation, the voltage gradient on the cable is greater close to the tower.

If sag is not considered in the tower construction shown in Fig. 1, symmetrical phase arrangements on the tower (ABC$\mathrm{ABC}$ ) normally give a higher prediction of current and voltage than asymmetrical phasing (i.e. ABC-CBA). This is evident in Figs. 9 and 10. When differential sag is included in modeling this is no longer the case. This is a key conclusion when considering application engineering for twin circuit towers.

To further assist understanding the shape of the voltage profiles Fig. 11 shows the magnitude of current along a given span. The real and imaginary components of the current are also shown. This is one way to demonstrate the changing phase of the resultant total current on the line. Karady et al show similar data using relative phase information [13]. The graph below is chosen because it assists in understanding how the physical origin of the currents affects their magnitude and direction. It can be seen how the voltage gradient on the cable is driving the direction of the real component of the current, whilst the imaginary component is controlled by capacitances. Their vector addition gives rise to the shape of the current magnitude.

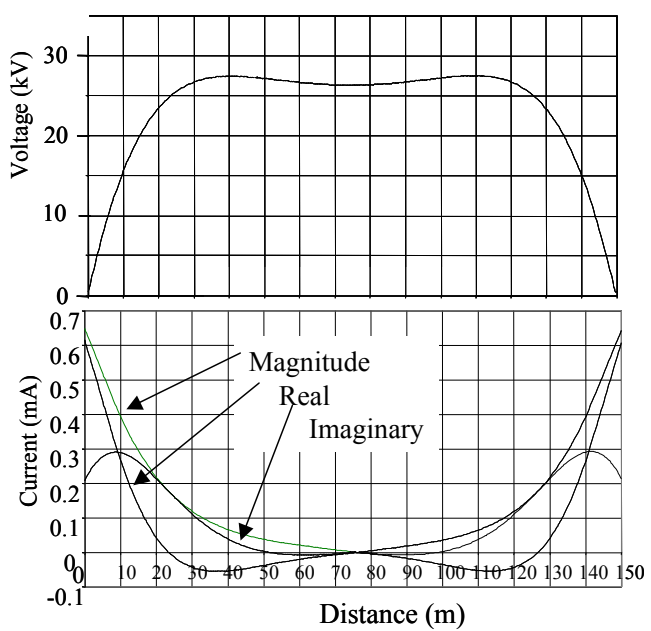

Fig. 11. The real and imaginary components of current as calculated by CDEGS for a $150 \mathrm{~m}$ span.

The effect of sag might also be investigated by considering the traditional view of space potential magnitude in the mid-span plan perpendicular to the cables, in conjunction with a superimposed phase map. Intuitively a clearer picture might be gained by considering the phase change in voltage as the position of the ADSS cable moves relative to the phase conductors along the span. Fig. 12 shows these plots for the tower geometry used in Fig. 4. Contours at a separation of 
approximately 15 degrees are shown. Clearly, as the ADSS cable changes position relative to the conductors, its voltage magnitude and/or phase is changed. The resulting changes in voltage phase are the reasons behind the changes in current seen in such cases compared to the situation of models with no differential sag. In these latter cases the ADSS cable is parallel to the conductors and the phase of the voltage does not change along its length.

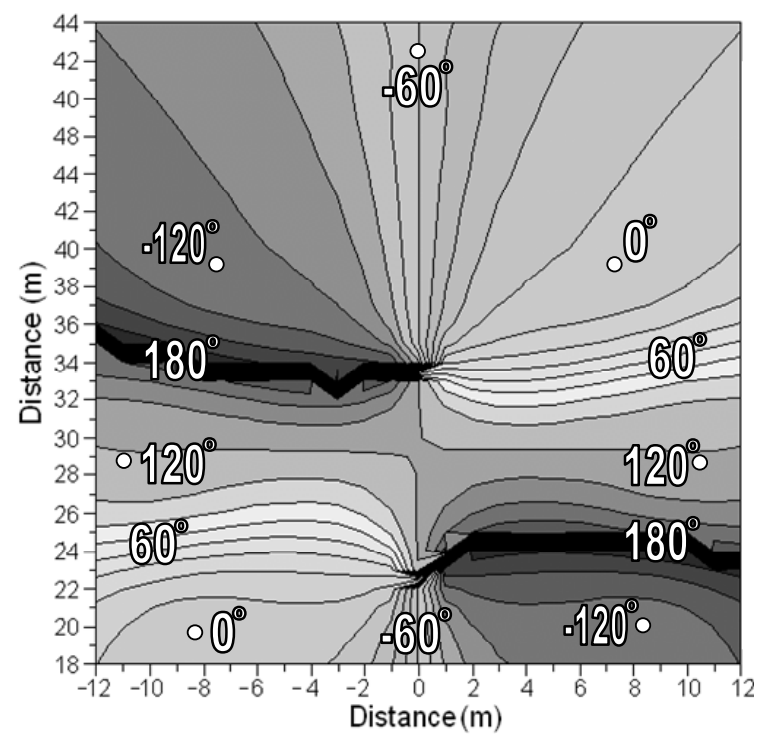

Fig. 12. Plot of angle contours of the space potentials in Fig. 4 for ABC-CBA phasing. The white circles indicate the conductors and earth wire positions.

\section{CONCLUSIOnS}

A model for predicting the currents and voltages imposed on an ADSS cable has been developed using the CDEGS platform. This model has been shown to be consistent with published models of other researchers.

The model shows that incorporating relative sag is critical to the determination of voltages and currents on the cable's surface. In cases of very high conductivity the tower does not impact the calculations significantly, but at typically realistic cable resistivity per unit length values of above $500 \mathrm{k} \Omega / \mathrm{m}$, the tower may be important in calculating the correct values. In the single and double circuit cases considered, ignoring the tower gives a worst case current.

Knowledge of pollution levels is critical to accurate predictions and this remains the weakest link in such calculations. Further work is required to understand material performance in differing environments in the presence of arcing. Conservative considerations can be used to judge the suitability of ADSS cable with various sheaths for specific applications, only if current calculations are used in conjunction with voltage profiles, which is not presently the common practice.

\section{REFERENCES}

[1] G. F. Moore, Electric Cables Handbook, 3rd Edition, Ed. Blackwell Science, pp. 685-752, 1997.

[2] U. H. P. Oestreich and H. M. Nassar, "Self-supporting dielectric fibre optical cables in high voltage lines," 37 th Proc. International Wire and Cable Symposium, pp. 79-82, 1988.

[3] C. N. Carter, "Arc controlling devices for use on self-supporting, optical cables,” IEE Proc. A, vol. 140, pp. 357-361, 1993.

[4] N. R. Haigh, S. M. Rowland, A. J. Taha, and C. N. Carter, "A fully instrumented installation and trial of a novel all-dielectric selfsupporting cable system for very high voltage overhead power lines," 45th Proc. International Wire and Cable Symposium, pp. 60-67, 1996.

[5] D. Wartschinski and F. Berger, "Test Methods for lifetime estimation of ADSS cables," Proc $14^{\text {th }}$ International Symposium on High Voltage Engineering, J-62, 2005.

[6] G. G. Karady, H. Qi, M. Reta-Hernandez, D. Srinivasan, and M Tuominen, "Sensor design for leakage current measurement on ADSS fiber-optic cable," IEEE Power Engineering Society Winter Meeting, vol. 1, pp. 281-286, 2001.

[7] S. M. Rowland and F. Easthope, "Electrical ageing and testing of dielectric, self-supporting cables for overhead power lines," Proc IEE Part A, vol. 140, pp. 351-356, 1993.

[8] S. M. Rowland and I. V. Nichols, "The effects of dry-band arc current on ageing of self-supporting dielectric cables in high fields," IEE Proc A- Sci. Meas. Technol., vol. 143, pp. 10-14, 1996.

[9] A. J. Peacock and J. C. G. Wheeler, "The development of aerial fibre optic cables for operation on $400 \mathrm{kV}$ power lines," IEE Proc. A, vol. 139, pp. 304-313, 1993.

[10] S. M. Rowland, "Sheathing materials for dielectric, aerial, selfsupporting cables for application on high voltage power lines," 6th IEE Conference on Dielectric Materials, Measurements and Applications, pp. 53-56, 1992.

[11] M. W. Tuominen and R. G. Olsen, "Electrical design parameters of alldielectric-self-supporting fibre optic cables," IEEE Trans Power Delivery, vol 15, pp. 940-947, 2000.

[12] C. N. Carter and M. A. Waldron, "Mathematical Model of dry-band arcing on self-supporting, all-dielectric optical cables strung on overhead power lines," IEE Proc. C, vol. 139, pp. 185-196, 1992.

[13] G. G. Karady, M. Tuominen, S. Devarajan and B. Han, "Computer simulation of fiber-optic cable failures due to dry-band arcing," IEEE Power Engineering Society Summer Meeting, pt. 2, pp. 890-4, 1999.

[14] C. N. Carter, J. Deas, N. R. Haigh, and S. M. Rowland, "Applicability of all-dielectric self-supporting cable system to very high voltage overhead power lines," 46th Proc. International Wire and Cable Symposium, pp. 624-631, 1997.

[15] A. J. Peacock and J. C. G. Wheeler, "The development of aerial fibre optic cables for operation on $400 \mathrm{kV}$ power lines," IEE Proc. A, vol. 139, pp. 304-313, 1993.

[16] A. G. W. M. Berkers, and J. M. Wetzwer, "Electrical Stresses on a self-supporting metal free cable on high voltage networks," IEE Conference on Dielectric Materials, Measurements and Applications pp. 69-72, 1988.

[17] A. J. Taha, I. V. Nichols, C. A. Platt and S. M. Rowland, "A novel system for the installation of all-dielectric self supporting optical cables on high voltage overhead power lines," 44th Proc International Wire and Cable Symposium pp. 171 - 177, 1995.

[18] Safe Engineering Services \& Technologies, "Hifreq user's manual", [Online document], [cited 2006 Jan 30], Available HTTP: http:/www.sestech.com/common/manual/engineering/hifreq.pdf 

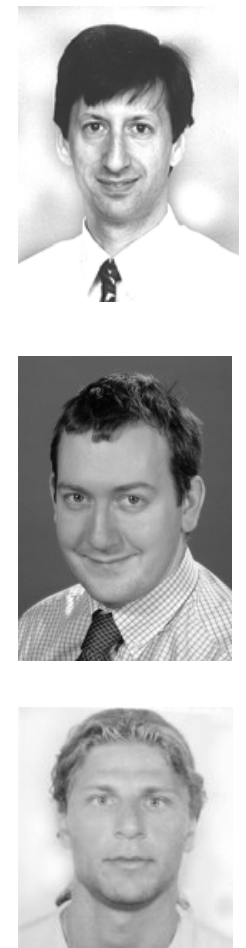

Simon M. Rowland (M'05) was born in West Ham, London, England. He completed his BSc in Physics at The University of East Anglia and his $\mathrm{PhD}$ at London University. Dr. Rowland was awarded the IEE Duddell premium in 1994 and became a Fellow of the IEE in 2000. He has worked in industrial research on dielectric materials and their applications. Since 2003 he has been a Senior Lecturer in the School of Electrical and Electronic Engineering in The University of Manchester.

Ian Cotton (M'98) received a Class I BEng (Hons) degree in Electrical Engineering from the University of Sheffield in 1995 and a PhD in Electrical Engineering from UMIST in 1998. Dr Cotton is now a lecturer in the Electrical Energy and Power Systems Group within the School of Electrical Engineering and Electronics at the University of Manchester. His current research interests include lightning protection, the effect of transients on the power system and the use of higher voltage systems in aerospace applications.

Konstantinos Kopsidas was born in Lefkas, Greece in 1977. He received his Higher Technological Education degree in Electrical Engineering from Institute of Piraeus (Athens) in 2002 and a Class I BEng (Hons) in Electrical \& Electronic Engineering from UMIST in 2004. He is currently studying for an MSc in Electrical Power Engineering in The University of Manchester. 